\title{
Building an Active Environmental-Chemical Engineering Research Program with Undergraduate Students
}

\author{
Jeffrey G. Sczechowski \\ Civil and Environmental Engineering Department \\ California Polytechnic State University \\ San Luis Obispo, CA 93407
}

\begin{abstract}
With a University-wide theme of "learn by doing", all Cal Poly undergraduates are required to complete a Senior Project. Environmental Engineering students are encouraged to conduct an experimental or an applied design project to fulfill this requirement. Students who select new faculty members as their advisors frequently find themselves in the midst of an on-going chemical engineering based environmental research project.

Since a student's time allocated for Senior Project is limited to the equivalent of four quarter units spanning a two quarter sequence, I have developed several procedures to facilitate the assimilation of students under my direction into these on-going projects. These procedures represent a unique combination of bringing research into the classroom, developing applied research skills in both lecture and laboratory courses, interactions with collaborative research groups, and individual instruction.

The results have been promising with one student going on to win the national Air and Waste Management Association (AWMA) award for the best student paper. Several other students are either planning to or have gone on to pursue graduate engineering degrees in either chemical or environmental engineering.
\end{abstract}

\section{INTRODUCTION}

Remember this scenario: A long, long time ago, in a graduate program far, far away, you were once baffled as how to start your M.S. or Ph.D. research. If you don't, then either you were born with the silver spoon of omnipotence or you are subconsciously blocking this traumatic experience. Seriously, embarking on that first independent research project, whether in graduate school or on the job, is intimidating. In many instances, the "research experience" claimed on our undergraduate resumes amounted to "gopher" work for a Ph.D. student desperately finishing their dissertation before the funding dried up. It did not prepare us properly.

When undergraduates perform outstanding research, and some really do, it is usually in a classic academic research environment with a few fringe benefits. The advisor must be dedicated to his or her undergraduate assistants. In addition, there are a few post-docs and a horde of graduate students working in well-equipped labs on funded projects willing to help. 
Now consider what it would be like for undergraduates to perform that same high caliber research outside of that nurturing environment. Assume that the advisor is just as dedicated to the students, but is also teaching three or four different courses each term. Gone are the postdocs, grad students, as well as most of the money and equipment. What is left is the new "undergraduate research institution", which ten years ago was happy with simply being known as an excellent undergraduate educational institution.

It may seem impossible for the students to conduct quality research in this sparse environment. Some funding agencies have indeed expressed that exact opinion in reviews of my proposals. The truth is they are correct, unless the research advisor develops an interactive program to assist the students. This program helps to overcome the both psychological intimidation and lack of experience problems that plague an undergraduate's first independent research project. Several methods for developing such a program at California Polytechnic State University (Cal Poly) are discussed below.

\section{The University}

Cal Poly is known for its excellence in undergraduate engineering education. Its educational philosophy of "learn by doing" has been the underlying reason for this success. Our students have a heavy lab component in their curricula to encourage "hands-on" skills. The strongest "learn by doing" component, however, is the required Senior Project course sequence, similar to a Bachelor's thesis.

\section{The Environmental Engineering Program (ENVE)}

The undergraduate Environmental Engineering (ENVE) Program is unique in that it combines the basic principles of chemical, mechanical, civil, and sanitary engineering in a technical curriculum to meet the current and future needs of the environmental engineering profession. This ABET accredited program evolved from a standard chemical engineering curriculum 30 years ago. It did not join with the Civil Engineering Program to form a department until 1984. Despite the title, the department is not the traditional Civil and Environmental (Sanitary) Engineering Department. The ENVE major and support courses are only slightly different than those found in most chemical engineering programs. It is easier to think of it as an environmental chemical engineering program.

\section{Senior Project}

The Environmental Engineering Senior Project is the application of undergraduate education to a problem typical of those which a graduate would be expected to solve when employed as an environmental engineer. It entails planning, research, and analysis of factors bearing on the problem, with conclusions and recommendations based upon the results gathered. The submission of a formal written report is also required. Undergraduates intrigued by research or drawn to a particular applied research area, usually find themselves working for one of the tenure-track faculty members, currently developing their research programs, to satisfy the Senior Project requirement. 


\section{GENERAL CONCEPT}

The main objective in our approach is to "teach" students how to research. This differs from most first experiences in research that involve "trial by fire". This latter approach does work, but it has obvious drawbacks. For example, it is not necessarily that the strong survive but in some cases it is the headstrong that survive. Many potentially excellent researchers, without an ego driven work ethic, are lost to other professions. They simply did not enjoy floundering in the lab or library, or on the computer, not knowing where to start. While I am not claiming the "excellent" moniker, I consider myself a solid researcher. I was, however, one of those who tossed in the towel (at least temporarily) after a frustrating Master's experience. Several of my friends who graduated with a B.S. in engineering described similar experiences. While some might attribute that to the type of people who are willing to consider themselves my friends, I think of it as evidence that "trial by fire" is not the best way to develop research skills.

Any competent professor could teach an undergraduate student how to conduct research with unlimited resources, especially, time. Since that is not the case, many student researchers unfortunately do not receive the proper guidance and instruction. When they develop research skills independently, it is usually at the expense of their advisor's project, funding, and equipment. In many instances, the advisor is stuck with only a preliminary study, if that. To teach students the research skills they need to complete a quality Senior Project and prepare them for similar work in their future careers, we employ the following:

\section{The Dedicated Course Option: ENVE 551}

Currently our unit operations lab (ENVE 551) is part of our graduate program but several undergraduates take the course as a technical elective. For various resource reasons, the course was not taught for 5 or 6 years prior to my arrival. When asked to revive the course, I found the equipment in a state of neglect and disrepair. To make things operational again, I pulled the classic academic trick of having the students enrolled in the course do the work for me. We have all probably been the "victims" of this approach during our undergraduate education. I still have nightmares about working on the fluidized bed back at Colorado. There are several published articles that explain variations of this method (1-3). I have used a similar approach with a unique twist during the past two years.

The students formed small collaborative groups to fix four different experimental apparatuses during the two 3-hour lab periods each week. I devoted the two hours of lecture each week to instructing the students on how to effectively develop a research project. This was possible since, as in most unit operations labs, the students have already studied the theory behind the equipment.

In order to "teach" research, I needed a little guidance and structure myself, since I learned my research skills "on the fly", so to speak. I found some excellent information in Folger and LeBlanc's book, Strategies for Creative Problem Solving and made it the required text for the course. I had the students apply the strategies presented in the book to their particular piece of equipment. Not everything was applicable, nor was every strategy appropriate for every student. Fortunately, Fogler and LeBlanc present several alternatives for enacting each step in their problem solving heuristic. The students could usually find something that worked for them. 
The book did not necessarily give these students the practical applied skills they needed to pursue their particular project. That was my job. I went about the task of bringing the experience and skills a good researcher and problem solver needs, into the classroom. This was done through a combination of helpful tips, wisdom, and personal experiences shared by a series of guest speakers and myself.

I typically cover subjects such as how to build a successful overall planning strategy (similar to the "risk pyramid" used in financial planning). Included in this are illustrations of the advantages and pitfalls of "quick and dirty" experiments to investigate hunches and possibilities. I also talk with students about how to deal with failure and use it to their advantage. Another subject is how to deal with conflicts or problems that arise in any project (moving targets, uncooperative collaborators, mangers, overly enthusiastic peer reviewers, etc.).

One lab period is spent in the library showing students where to find "things", ranging from vendors to scientific publications. During this session, the students scour the Thomas Register and scientific supply catalogs to find vendors of quirky accessories that may assist me in a current research project. For example, "Find a large, long-wave UV transparent liquid crystal shutter for me." This type of instruction for first-time researchers is vital. Most experienced academics take this information management skill for granted. We do it without thinking, or have a Ph.D. student do it for us (to guarantee we won't have to think).

Guest speakers address other aspects of conducting applied research and development. The subjects of their presentations are listed in Table I. The speakers are from every segment of the campus and are recognized gurus on their subjects. Along with the information in the text, we present a fairly complete picture of what constitutes quality research and how to do it.

At the beginning of the endeavor, students are very eager and motivated. This is later tempered by the first major problem they encounter that cannot be solved in 5 minutes. When they are really stuck, I step in to jump-start the problem solving process. Through active discussions students observe how I think things out, implement my ideas, and test their validity. This is almost impossible to do on an individual basis. Since the students work in small groups, it is more manageable as well as more active and productive.

By the middle of the quarter, the students usually panic. "So much to do, and so little time" syndrome coupled with, "Why didn't I listen to that guest speaker talking about project management and critical path?" fuels the fire. Most students work though this but instructor intervention helps them re-define the problem in a workable scope.

At the end of the quarter, they are confident about their ability to conduct experimental investigations or tackle a variety of trouble-shooting problems. This is evident both in their discussions with me and in my observations of their discussions with peers, as well in comments from anonymous course evaluations. 


\section{Other Future Courses}

I am currently responsible for developing a new Environmental Protection Engineering Laboratory (EPEL). The EPEL is a $\$ 150,000$ project sponsored by the Cal Poly Plan. It will be completed in time for the 1997 Fall quarter. In this new facility, students will experiment with innovative physical, chemical, and biological treatment processes for industrial and hazardous waste. They will be required to enroll in at least one of the three courses taught in the EPEL. While the specific types of waste treatment will differ, the goals of the courses will be similar. In the EPEL courses, students will participate in a structured approach to learn how to conduct an applied engineering study.

In addition to the principles, operation, and optimization of the various treatment technologies, students will also learn how to use the analytical instruments (GC, HPLC, IC, TOC, etc.) required to monitor the effectiveness of these processes. Focusing on the higher level learning skills, students will be required to analyze and explain their own results as well as make comparisons to previous work by their peers and that found in published studies. In the latter half of the class, students will be challenged to design and run experiments to prove a hypothesis they formulated rather than one that was assigned in a lab manual. The students will also participate in class-wide peer reviews simulating the journal publication process.

Upon completing at least one EPEL course, the students will be better prepared to generate a quality Senior Project. They will be able to accomplish something significant in the two-quarter Senior Project course sequence. The students will have a solid grasp of the scientific method as well as the psychological motivation that they can have an immediate impact on a research project. They will be able to design and run experiments, order equipment, test the validity of their results, and develop meaningful conclusions similar to an experienced graduate researcher, but on a smaller time scale mostly due to time constraints. Should they continue with a professional or academic research career, they would be prepared to grapple with complex problems the day they are assigned. Many of the creative problem solving skills developed in the EPEL will apply to all types of engineering problems as well as other problems encountered in their professional careers. It may even help them solve a few problems in their personal lives (such as, how to assemble their kids' toys on Christmas Eve, after their spouse is no longer a rational human being).

\section{Past and Current Senior Projects}

While the EPEL and its courses are under construction, I have used several techniques in the Senior Project course sequence to facilitate undergraduate research. One of the most helpful administrative ideas has been writing up a clear list of ground-rules, expectations, and deadlines enforced by a signed contract. Because of their ridiculously busy and unpredictable schedules, undergraduates live by deadlines. A series of short tasks (summary statements, outlines, timetables, preliminary reports, status memos, etc.) distributed throughout the Senior Project time-frame give direction and contribute to the overall organization and project goals. If I can keep them on track early in the process, when the students do encounter those typically unpredictable problems during the experimental stage, they feel they have enough time and interest invested in the project to hammer through these rough spots. 
My colleagues and I also use a variety of other strategies that include, demonstrations of computer literature searches, self guided technical writing workshops, project planning, and field trips to related facilities. About $50 \%$ of the students collaborate in two or three member teams, which helps tremendously. In many instances, team members will brainstorm and problem solve on their own leading to some very creative solutions and reducing their dependence on their advisor.

Additional techniques for future Senior Projects include requiring the students to attend the portion of the graduate seminar class devoted to "How to Get Things Done" leveraged from the ENVE 551 course material. I am also trying to organize a regular research group meeting but that has been difficult with the busy schedules our students have. A point discussed below in more detail.

\section{OTHER CONSIDERATIONS}

While this "learn by doing" (with proper guidance) instructional research technique has been very effective so far, there are some administrative problems that require creative problem solving on the part of the advisor.

\section{Time: Yours and Theirs}

While teaching research to the masses saves time, there are still some incredible demands on my time with this approach. It is similar to preparing for a separate course in addition to my other three courses. Fortunately, there is a return on the investment. As with teaching anything, it becomes easier after you have obeyed the "Rule of Three". Teaching something the first time takes enormous amounts of time and energy. Teaching it a second time leaves you more confused than the first. Finally during the third time you feel comfortable with the material (well, sort of). Other benefits include a few journal caliber publications in the works and my lab is nearly set-up almost exclusively with student help. This included the lab layout, facility recommendations, and renovations (some of our students are excellent carpenters).

I consider my time precious like all professors, but when I look at an upper division undergraduate engineering student's schedule, I shudder. Unlike graduate students, undergraduates have to be in designated places all the time. Between the courses, labs, student society functions, and meetings for all those cooperative homework groups that we require, these kids are phenomenally busy. Some days, students barely have time to think (as you've seen on exams), much less design and run an experiment in the lab.

\section{"Show Them The Money!"}

Many of my students have part-time jobs to help pay for their education. While they are learning to be responsible, interacting with the community, and being able to feed themselves, there is one major problem. They are not working in my lab when they are working somewhere else. OK, I agree this sounds a little selfish, but it has some merit, and fortunately an easy solution. Whenever possible, I pay students a nominal wage of $\$ 5 /$ hour to $\$ 6 /$ hour for up to 15 hours a week (more in the summer). In most cases they will gladly work on an engineering research project rather than flip burgers, bag groceries, or work in bicycle shops on the weekends. 
Unfortunately, the money usually comes from any summer salary or added compensation I tried to secure for myself, but in the end, it is worth it. Now that I am writing research proposals, undergraduate wages are always a major component in the budget.

\section{CONCLUSIONS}

Professors at research universities have been increasing the number of undergraduate students in their research groups with impressive results. Basing an entire research program on undergraduates is another story. It is not easy, but with the proper training and attention, undergraduates can quickly assimilate the skills required to work on complex research projects. It works. One of my Senior Project students took the ENVE 551 course in the middle of his Senior Project work. He went on to win the national undergraduate paper competition at the 1996 Air and Waste Management Association's Annual Conference for his research in heterogeneous photocatalysis.

Conducting research with undergraduates requires that organization and structure be provided by the advisor, as well as considerable time and patience. The main point is that undergraduate students can be taught how to research just as they are taught any other subject. They just need quality instruction to capitalize on the fairly short period they can devote to a research project in their busy curricula. Thus, at an undergraduate "research" institution, it pays to be a good teacher first. It makes the research go a little smoother.

On occasion events take a turn for the worse. Some students bail out just as they begin collecting their first solid data. They may miss a deadline on occasion, which sometimes requires me to work a few more days of a quarter break. Missed deadlines have also kept me from incorporating some preliminary results in a proposal. In addition, students break things in the lab. Some days I think that I should chuck all this and do the work myself. Three revelations usually convince me that I shouldn't. First, I would not complete a fraction of the work that several students do during the year. Second, since Senior Project is a requirement, I am required to be an advisor. This obviously takes time, why not use that to my advantage? Finally, when I work in the lab, I break things. In most cases, broken stuff is solid evidence that people are working hard and hopefully learning from their mistakes. Of course, that is especially true when I am the one breaking things.

\section{REFERENCES}

1. Amon, C., Finger, S., Siewiorek, D. Smailagic, A., "Integrating Design Education, Research and Practice at Carnegie Mellon”, Journal of Engineering Education, Vol. 85, (4), 1996, pp. 279-285.

2. Middelberg, A., "Laboratory Projects: Should Students Do Them or Design Them”, Chemical Engineering Education, Vol. 29 (1), 1995, pp. 34-38.

3. Meade, J., "Envisioneers", Prism, December, 1994, p.17.

4. A lesson learned from Richard Felder's "Teaching Effectiveness for Engineering Professors", Raleigh, NC, 1994. 


\section{BIOGRAPHICAL INFORMATION}

JEFFREY G. SCZECHOWSKI

Jeff Sczechowski is an Assistant Professor of Environmental Engineering at Cal Poly. He obtained his B.S. and Ph.D. degrees in Chemical Engineering from the University of Colorado (1985 and 1994), and his M.S. in Chemical Engineering from N.C. State University (1988). Along with juggling his teaching load, he tries to continue his research in advanced oxidation processes, particularly heterogeneous photocatalysis, and keep up with his 2 kids. 